This is an author produced version of a paper published in J Comp Neurol. This paper has been peer-reviewed but does not include the final publisher proof-corrections or journal pagination.

Citation for the published paper:

Persson S, Boulland JL, Aspling M, Larsson M, Fremeau RT Jr, Edwards RH, Storm-Mathisen J, Chaudhry FA and Broman J.

"Distribution of vesicular glutamate transporters

1 and 2 in the rat spinal cord, with a note on the spinocervical tract."

J Comp Neurol. 2006 Aug 10; 497(5):683-701. 10.1002/cne.20987

Access to the published version may require journal subscription. Published with permission from: Wiley 


\section{Distribution of vesicular glutamate transporters 1 and 2 in the rat spinal cord, with a note on the spinocervical tract}

Stefan Persson ${ }^{1}$, Jean-Luc Boulland ${ }^{2}$, Marie Aspling ${ }^{1}$, Max Larsson $^{1}$, Robert T. Fremeau Jr. ${ }^{3}$, Robert H. Edwards ${ }^{3}$, Jon Storm-Mathisen ${ }^{2}$, Farrukh A. Chaudhry ${ }^{2}$ and Jonas Broman ${ }^{1}$

${ }^{1}$ Department of Experimental Medical Science, Division for Neuroscience, Lund University, BMC F10, S-221 84 Lund, Sweden

${ }^{2}$ Institute of Basic Medical Sciences and Centre for Molecular Biology and Neuroscience, University of Oslo, Sognsvannsveien 9, P.O. Box 1105 Blindern, N-0317 Oslo, Norway

${ }^{3}$ Departments of Neurology and Physiology, Graduate Programs in Neuroscience and Cell Biology, University of California San Francisco School of Medicine, San Francisco, California 94143, USA

Abbreviated title: VGLUT1 and VGLUT2 in rat spinal cord

Associate Editor: Dr. Gert Holstege

Indexing terms: dorsal horn; ventral horn; immunocytochemistry; excitatory amino acid; lateral cervical nucleus

Correspondence to: Jonas Broman

Department of Experimental Medical Science, Section for Neuroscience, Lund University, BMC F10, S-221 84 Lund,

Sweden

Telephone: +46462227781

FAX: $\quad+46462224546$

Email: jonas.broman@med.lu.se

Support information:

Grant sponsor: Swedish Research Council; Grant number: 14276; Grant sponsor: Norwegian Research Council (RCN); Grant sponsor: National Institute of Health; Grant sponsor: Crafoordska Stiftelsen; Grant sponsor: Thorsten och Elsa Segerfalks Stiftelse. 


\section{ABSTRACT}

To evaluate if the organization of glutamatergic fibers systems in the lumbar cord is evident also at other spinal levels, we examined the immunocytochemical distribution of vesicle glutamate transporters 1 and 2 (VGLUT1, VGLUT2) at several different levels of the rat spinal cord. We also examined the expression of VGLUTs in an ascending sensory pathway, the spinocervical tract, and co-localization of VGLUT1 and VGLUT2.

Mainly small VGLUT2-immunoreactive varicosities occurred at relatively high densities in most areas, with the highest density in laminae I-II. VGLUT1 immunolabeling, including small and medium-sized to large varicosities, were more differentiated with the highest density in the deep dorsal horn and in certain nuclei as the internal basilar nucleus, the central cervical nucleus and the column of Clarke. Lamina I and IIo displayed a moderate density of small VGLUT1 varicosities at all spinal levels, although in the spinal enlargements a uniform density of such varicosities were evident throughout laminae I-II in the medial half of the dorsal horn. Corticospinal tract axons displayed VGLUT1, indicating the corticospinal tract as an important source of small VGLUT1 varicosities. VGLUT1 and VGLUT2 were cocontained in small numbers of varicosities in laminae III-IV and IX. Anterogradely labeled spinocervical tract terminals in the lateral cervical nucleus were VGLUT2 immunoreactive.

In conclusion, the principal distribution patterns of VGLUT1 and VGLUT2 are essentially similar throughout the rostrocaudal extension of the spinal cord. The mediolateral differences in VGLUT1 distribution in laminae I-II suggest dual origins VGLUT1 immunoreactive varicosities in this region. 


\section{INTRODUCTION}

The first observations that the amino acid glutamate has a powerful excitatory action on neurons in the central nervous system, including those in the spinal cord, date back to the 1950's and early 1960's (Hayashi, 1954; Curtis and Watkins, 1960). However, it took a long time before the concept that glutamate functions as a neurotransmitter was generally accepted, due to the fact that glutamate, in contrast to most other transmitter substances, is present in high concentrations in the brain and is also a crucial component in neuronal metabolism and protein synthesis. Subsequently, glutamate was shown to fulfill the criteria of a neurotransmitter and is now generally accepted as the neurotransmitter in the majority of excitatory synapses in the central nervous system (Fonnum, 1984; Krnjevic, 1986; Watkins, 1986; Broman et al., 2000, 2004).

Identification of the neurons and nerve terminals that release glutamate has been hampered by the absence of reliable markers that could be used to label such profiles in tissue sections. Combinations of lesions and biochemical assays have been of value in identifying foremost massive glutamatergic projections such as certain corticofugal tracts (e.g. Fonnum, 1984). Autoradiographic detection of retrogradely transported $\mathrm{D}-\left[{ }^{3} \mathrm{H}\right]$ aspartate has been a useful marker of also small glutamatergic projections, although this technique does not label all neurons that are presumed to use glutamate as a neurotransmitter (Baughman and Gilbert, 1980, Streit, 1980; Ottersen, 1991). With the production of antibodies that recognize aldehyde-fixed glutamate in tissue sections, a most valuable tool for studies of glutamate distribution was introduced (Storm-Mathisen et al., 1983). As glutamate is present in essentially all cellular elements in the central nervous system, it is necessary to use labeling techniques that allow a quantitative analysis and comparison of the labeling of nerve terminals and other tissue profiles. Such a technique is electron microscopic postembedding immunogold labeling, which has been used in a large number of studies to identify putative glutamatergic terminal populations in many parts of the central nervous system including the spinal cord (Broman et al., 2000). However, due to the ubiquitous presence of glutamate and the relatively small differences in glutamate content between glutamatergic terminals and certain other tissue elements, glutamate immunolabeling is usually of limited value for visualizing glutamatergic fiber systems in tissue sections by light microscopy.

A property that differentiates glutamatergic neurons from non-glutamatergic neurons is their ability to accumulate glutamate in synaptic vesicles prior to exocytotic release (Naito and Ueda, 1985; Maycox et al., 1988; Fykse et al., 1989; Winter and Ueda, 1993). Thus, the 
transporters responsible for vesicular glutamate uptake may serve as selective markers for glutamatergic neurons. Recent studies have identified three different vesicular glutamate transporters (Aihara et al., 2000; Bellocchio et al., 2000; Takamori et al., 2000; Fremeau et al., 2001, 2002; Herzog et al., 2001; Gras et al., 2002; Schäfer et al., 2002; Takamori et al., 2002; Varoqui et al., 2002). Vesicular glutamate transporters 1 and 2 (VGLUT1, VGLUT2) are expressed throughout the central nervous system in numerous neurons believed on other grounds to use glutamate as neurotransmitter. Generally, VGLUT1 and VGLUT2 show a complementary expression pattern in the brain (Fremeau et al., 2001; Varoqui et al., 2002). It has been suggested, among others, based on differential expression of these isoforms in mammalian cells, that they define two distinct classes of glutamatergic synapses (Fremeau et al., 2001). In contrast, the vesicular glutamate transporter 3 (VGLUT3) is expressed in a variety of cells, including GABAergic and monoaminergic neurons as well as astrocytes (Fremeau et al., 2002; Gras et al., 2002; Boulland et al., 2004). Transient expression of VGLUT3 has also been detected in progenitor cells, and it has been suggested that VGLUT3 may rather have a morphogenetic role during development and a modulatory role on synaptic transmission at non-glutamatergic synapses in the adult (Boulland et al., 2004).

Glutamatergic synaptic transmission plays a fundamental role in several subregions of the spinal cord (Broman et al., 2004). However, immunocytochemical localization of VGLUT1 and VGLUT2 in the spinal cord has so far focused on select levels or fiber systems (Kaneko et al., 2002; Varoqui et al., 2002; Li et al., 2003; Todd et al., 2003; Oliveira et al., 2003; Landry et al., 2004; Alvarez et al., 2004; Herzog et al., 2004). It is therefore uncertain if the conclusions inferred from examination of primarily lumbar levels can be generalized to other rostrocaudal levels of the spinal cord. Further, the distribution patterns of VGLUT1 and VGLUT2 in spinal nuclei present only at non-lumbar levels are unknown. In the present study we examine the detailed distribution and appearance of VGLUT1 and VGLUT2 immunolabeled varicosities at several rostrocaudal levels of the spinal cord and describe certain distribution patterns not previously examined or recognized. Further, we demonstrate that varicosities of the spinocervical tract, an intraspinal sensory pathway, contain VGLUT2.

\section{MATERIALS AND METHODS}

\section{Animals}


Subject of the study were adult male or female Sprague-Dawley or Wistar rats weighing 250$400 \mathrm{~g}$. The experimental procedures were made according to the European regulations and were approved in advance by the local Animal Care and Use Committees.

\section{Antisera}

The antisera used in this study are listed in Table 1. All three VGLUT1 antisera used produced staining patterns in the spinal cord indistinguishable from each other, as did the two VGLUT2 antisera. Western blot analysis of homogenized rat brains and/or crude synaptic vesicle fractions from rat brains demonstrated a single broad band at about $60 \mathrm{kDa}$ for all three VGLUT1 antisera and a single broad band slightly above $60 \mathrm{kDa}$ for the two VGLUT2 antisera (Bellocchio et al., 1998; Fremeau et al., 2001; Boulland et al., 2004; Boulland, Chaudhry and Storm-Mathisen, unpublished observations; Antibody data sheets from Synaptic Systems). In COS or PC12 cells transfected with VGLUT1 or VGLUT2 cDNA, immunolabeling with the VGLUT1 and VGLUT2 antisera of Bellocchio et al. (1998) and Fremeau et al. (2001) were only evident when the antisera were applied to cells expressing the corresponding transporter isoform. Furthermore, pre-adsorption of these antisera with the corresponding, but not with the non-corresponding, GST fusion protein used as immunogen, completely abolished immunolabeling of rat brain sections (Bellocchio et al., 1998; Fremeau et al., 2001; Boulland et al., 2004). Similarly, pre-adsorption of the Synaptic System VGLUT1 and VGLUT2 antibodies with the corresponding, but not with the noncorresponding, immunogen ( $5 \mu \mathrm{g} / \mathrm{ml}$ diluted antiserum), eliminated all staining in rat spinal cord sections, except for some faint background mainly present in neuronal cell bodies (not shown). This faint background, and an absence of nerve terminal-like labeling, was also evident in sections processed for immunolabeling with normal rabbit serum in place of VGLUT1 or VGLUT2 antiserum. In conclusion, the above control experiments strongly suggest that the VGLUT1 and VGLUT2 immunolabeling reported in this study represents the presence of VGLUT1 and VGLUT2, respectively, in select spinal cord fibers systems.

The mouse monoclonal antibody used for detection of choleragenoid (cholera toxin subunit $\mathrm{B}, \mathrm{CTb}$ ), reacts selectively with the beta chain of the toxin according to ELISA analysis performed by the manufacturer. Sections from the brain and spinal cord of rats not injected with $\mathrm{CTb}$ demonstrate no immunolabeling when processed with this antibody, except for some labeling in parts of the area postrema and the medial eminence (i.e., sites with absent 
blood-brain barrier). This labeling is evident only when the primary antibody is detected with the rabbit anti-mouse antiserum and the mouse monoclonal peroxidase/anti-peroxidase from Dako (i.e., not when detected with the Alexa 488-conjugated antibody) and is also present when sections are processed with other mouse monoclonal antibodies (unpublished observations). Pre-adsorption of the diluted anti-CTb antibody with $\mathrm{CTb}(5 \mu \mathrm{g} / \mathrm{ml})$ completely abolished labeling of injected and axonally transported $\mathrm{CTb}$ in rats with spinal $\mathrm{CTb}$ injections. In conclusion, the $\mathrm{CTb}$ labeling detected with this antibody in the lateral cervical nucleus most likely identifies spinocervical tract terminations originating from the sites of $\mathrm{CTb}$ injections in the spinal cord.

\section{VGLUT immunoperoxidase labeling}

Spinal cord sections from six Sprague-Dawley rats were used for VGLUT1 and VGLUT2 immunoperoxidase labeling. Deep anesthesia was induced by an overdose of sodium pentobarbital i.p. and the rats were fixed by transcardial perfusion. Following a rinse with 100-200 $\mathrm{ml}$ of phosphate buffered saline (PBS, pH 7.4, $300 \mathrm{mOsm}$ ) the rats were perfused for 20-25 minutes with $800-1000 \mathrm{ml}$ of $4 \%$ (w/v) depolymerized paraformaldehyde in PBS. The spinal cord was then uncovered and in all rats segments C2, C6, T8 or T9 and L4 were harvested, postfixed in the same fixative for two hours and then placed in $30 \%(\mathrm{w} / \mathrm{v})$ sucrose in PBS overnight at $4^{\circ} \mathrm{C}$. In some rats were also parts of adjacent segments harvested and processed. The caudal border of each segment was defined as the level of entrance of its caudal-most dorsal rootlet.

Each spinal cord segment was sectioned transversely on a freezing microtome at $40 \mu \mathrm{m}$. In each group of five serial sections, one was processed for VGLUT1 immunolabeling and another for VGLUT2 immunolabeling. In some of the rats a third section in each group was mounted on slides and stained with thionin. The sections processed for immunolabeling were first blocked for two hours in normal swine serum (DAKO; 1:30) diluted in PBS containing $0.5 \%(\mathrm{w} / \mathrm{v})$ bovine serum albumin (Sigma) and 0.5\% (v/v) Triton X-100 (Sigma) (PBST). The sections were then incubated free-floating in PBST solutions of primary antibody for two days at room temperature under gentle agitation. For VGLUT1 immunolabeling, either of two different rabbit polyclonal antisera were used, one produced by Bellocchio et al. (1998; diluted 1:4000) or one commercially obtained (Synaptic Systems; diluted 1:2000-4000). Similarly, for VGLUT2 immunolabeling, either the antiserum produced by Fremeau et al. 
(2001; diluted 1:20,000-40,000) or the VGLUT2 antiserum obtained from Synaptic Systems (diluted 1:2000) was used. The concentrations of antibodies were chosen to produce similar staining intensities in the areas most strongly immunoreactive for VGLUT1 and VGLUT2, respectively. To reduce background staining, all primary antibody solutions were preabsorbed with fixed rat liver sections overnight prior to use.

Following the incubation in primary antibody, the sections were rinsed $6 \times 10$ min in PBS and then incubated in biotinylated swine anti-rabbit (1:30; DAKO) in PBST for one hour. The sections were then rinsed in PBS ( 3 x 10 min) and incubated in Vectastain ABC Elite solution (Vector; 1 drop each of solutions A and B in $5 \mathrm{ml}$ PBST) for three hours. After further rinses in PBS (3 x $10 \mathrm{~min}$ ), the sections were processed with the chromogen Vector SG (Vector) to visualize the distribution of bound immuno-complexes. The sections were then rinsed, mounted on slides with a chrome alum gelatin solution and air-dried overnight. Following dehydration in graded ethanols, the sections were cleared in xylene overnight and then coverslipped with DPX (BDH). The sections were examined in a light microscope and photographed with a Polaroid DMC 1 digital microscope camera. Photomicrographs were obtained with a X100 oil-immersion lens (Fig. 1), a X10 lens (Fig. 3), or a X40 lens (Figs. 47), and mounted and moderately processed in Photoshop (levels, contrast/brightness) to enhance the visibility of labeled profiles.

In six different areas of spinal gray matter (laminae I-II, laminae III-IV, laminae V-VI, lamina VII, lamina VIII and lamina IX) the long diameter of 100 labeled varicosities was measured in each area in two sections from L4 labeled for VGLUT1 or VGLUT2, respectively. Measurements were made using functions in Photoshop on digital photomicrographs obtained with a X100 oil-immersion lens and enlarged to X10,000 on the computer screen. The medium-sized VGLUT1 immunolabeled varicosities in the inner part of lamina II, spatially closely associated with the population of similar varicosities in laminae III-IV, were not included in the analysis of VGLUT1 immunolabeled varicosities in laminae I-II.

\section{Immunofluorescent labeling of the spinocervical tract}

To examine if terminals of the spinocervical tract contain VGLUT1 and/or VGLUT2, three Sprague-Dawley rats were anesthetized with sodium pentobarbital (60-70 mg/kg b.w., i.p.) and either the cervical (2 rats) or the lumbar (1 rat) spinal enlargement was uncovered by 
laminectomies. Using a glass micropipette connected to a Hamilton syringe, choleragenoid (CTb, 1\%; List Biological Laboratories) was injected unilaterally into the dorsal horn (five injections of $0.1 \mu \mathrm{l}$ each, each spaced about $1 \mathrm{~mm}$ in the rostrocaudal axis). The wound was sutured and the rats allowed to survive for three (cervical injections) or eight (lumbar injections) days. The rats were then deeply anesthetized and fixed by transcardial perfusion as described above. The spinal cord segments containing the injections sites and the C1-3 segments containing the lateral cervical nucleus were harvested and placed in PBS with 30\% sucrose overnight.

Parasagittal sections through the injection sites were obtained at $40 \mu \mathrm{m}$ using a freezing microtome. Every fifth section was processed sequentially (with intervening rinses in PBS) in mouse monoclonal anti-CTb (Biogenesis; 1:500), rabbit anti-mouse antiserum (Dako; 1:50), mouse monoclonal peroxidase/anti-peroxidase (Dako; 1:120) and the chromogen Vector SG (Vector) to visualize injected $\mathrm{CTb}$. Light microscopic examination of mounted sections demonstrated large injections, most centered in the deep dorsal horn, covering major parts of the spinal gray matter for a rostrocaudal distance of about $5 \mathrm{~mm}$ in the cervical or lumbar enlargement.

The C1-3 segments were cut transversely on a freezing microtome at $40 \mu \mathrm{m}$. In each group of ten consecutive sections, one section was processed for CTb and VGLUT1 immunolabeling and another section for $\mathrm{CTb}$ and VGLUT2 immunolabeling. The sections were incubated for two days at room temperature in a mixture in PBST of mouse monoclonal anti-CTb (1:500) and rabbit anti-VGLUT1 (Synaptic Systems; 1:2000) or rabbit antiVGLUT2 (Synaptic Systems; 1:2000). Following several rinses in PBS, the sections were incubated for one hour in a mixture of Alexa 488-conjugated donkey anti-mouse and Alexa 594-conjugated donkey anti-rabbit (Molecular Probes), both diluted 1:4000 in PBST. The sections were then rinsed in PBS, mounted on slides, air-dried overnight, and cover-slipped with ProLong Gold antifade reagent (Molecular Probes).

The sections were examined in a Zeiss LSM 510 confocal laser scanning microscope, first using conventional epifluorescence microscopy with a X5 lens to identify areas in the lateral cervical nucleus containing $\mathrm{CTb}$ labeled varicosities, and then with confocal microscopy using a X100 oil-immersion lens. To minimize cross talk between the green (500$550 \mathrm{~nm})$ and red $(\geq 560 \mathrm{~nm})$ channels, images were acquired in sequence, rather than simultaneously, so that the detector for $500-550 \mathrm{~nm}$ was deactivated while the $543 \mathrm{~nm}$ argon laser was on and vice versa. 
Several z stacks, of varying depth, were sampled and used in the analysis of double labeling. In some sections, single $1-\mu \mathrm{m}$-thick optical slices in one or two 92 X $92 \mu \mathrm{m}$ large fields in the lateral cervical nucleus, were also sampled. Care was taken to completely separate the selected fields to avoid sampling of individual varicosities twice.

The $\mathrm{z}$ stacks were displayed on the computer screen, with the red and green channels side by side, together with a merged red/green image. Varicosities labeled for $\mathrm{CTb}$ were identified in the green channel and the corresponding locations in the red and merged channels were inspected in order to determine whether the varicosity were immunolabeled also for VGLUT1 or VGLUT2. In cases where double labeling was uncertain, varicosities were followed through the individual optical slices of the $\mathrm{z}$ stack to determine if the VGLUT staining located within the CTb-labeled varicosity or not. Single optical slices were separated into red and green channels, and these were analyzed using the Cell Counter plugin in NIH ImageJ v. $1.34 \mathrm{e}$.

\section{Double immunofluorescence labeling for VGLUT1 and VGLUT2}

Wistar rats were deeply anesthetized and fixed by transcardial perfusion by means of a peristaltic pump at a flow rate of about $25 \mathrm{ml} / \mathrm{min}$ and per $100 \mathrm{~g}$. A brief flush of $4 \%$ dextran $(\mathrm{w} / \mathrm{v})$ in $0.1 \mathrm{M}$ sodium phosphate buffer $\mathrm{pH} 7.4(\mathrm{NaPi})$ was followed by $4 \%$ formaldehyde (freshly depolymerized from paraformaldehyde in $0.1 \mathrm{M} \mathrm{NaPi}$ ). The $\mathrm{C} 1-\mathrm{C} 2$ spinal cord segments were dissected out and post-fixed overnight in the fixative at $4^{\circ} \mathrm{C}$. The tissue was cryoprotected in $30 \%$ sucrose diluted in $\mathrm{NaPi}$ with $0.05 \%$ (w/v) $\mathrm{NaN}_{3}$ at $4^{\circ} \mathrm{C}$.

Transverse cryostat sections $(10-15 \mu \mathrm{m})$ were rinsed once for $5 \mathrm{~min}$ in PBS and incubated for $10 \mathrm{~min}$ in $1 \mathrm{M}$ ethanolamine (adjusted to $\mathrm{pH} 7.4$ with $\mathrm{HCl}$ ) in $0.1 \mathrm{M} \mathrm{NaPi}$. Sections were rinsed $3 \times 5 \mathrm{~min}$ in PBS and unspecific binding sites blocked for one hour with $10 \%(\mathrm{v} / \mathrm{v})$ normal goat serum (NGS), $1 \%(\mathrm{w} / \mathrm{v})$ BSA, and 0.5\% (w/v) Triton X-100 in PBS (pH 7.4).

Double immunofluorescence labeling of VGLUT1 and VGLUT2 was made either by simultaneous incubation in antisera from different species or by sequential incubations in antisera from the same species. In the first protocol, sections were incubated overnight at room temperature in a mixture of guinea pig VGLUT1 antibody (Chemicon; 1:5000) and rabbit VGLUT2 antibody (Fremeau et al., 2001; 1:1000) in diluent solution, consisting of PBS with $3 \%(\mathrm{v} / \mathrm{v})$ NGS, $1 \%(\mathrm{w} / \mathrm{v})$ BSA, $0.5 \%(\mathrm{w} / \mathrm{v})$ Triton $\mathrm{X}-100$, and $0.05 \%(\mathrm{w} / \mathrm{v}) \mathrm{NaN}_{3}$. After 3 x 5 minutes rinsing in diluent solution, sections were incubated for one hour in a mixture of secondary antibodies (goat anti-guinea pig coupled to $\mathrm{Cy} 3,1: 500$; goat anti-rabbit 
coupled to Cy2, 1:1000; Molecular Probes Inc., Eugene, Oregon, USA) in diluent solution. The sections were then rinsed in PBS and mounted with Fluoromount G (Southern Biotechnology Associates Inc., Birmingham, Alabama, USA).

A protocol for double labeling using primary antibodies from the same host species was developed from previous reports (Wessel and McClay, 1986; Franzusoff et al., 1991; Lewis Carl et al., 1993). The solution used for dilution of antisera and rinsing was the same as above unless noted. Sections were incubated overnight at room temperature in rabbit VGLUT1 antibody (Bellocchio et al., 1998; 1:1000). Following 3 x 5 minutes of rinsing, the sections were incubated in goat anti-rabbit coupled to Cy2 (1:500; Molecular Probes). The sections were then rinsed ( 3 x 5 minutes) and incubated for 1 hour with rabbit preimmune $\operatorname{IgG}(12$ $\mathrm{mg} / \mathrm{ml}$; serum purified from a protein A column as descried in Boulland et al., 2002) to block secondary antibody free arms. Following another rinse ( 3 x 5 minutes), the sections were incubated for one hour with goat anti-rabbit monovalent Fab (Jackson ImmunoResearch Laboratories Inc., West Groove, PA, USA) at $70 \mathrm{mg} / \mathrm{ml}$ to block rabbit Ig epitopes. The sections were then rinsed $3 \times 10$ min in PBS and fixed for 30 min with 4\% formaldehyde dissolved in $0.1 \mathrm{M} \mathrm{NaPi}$. After rinsing $3 \times 10 \mathrm{~min}$ in PBS, sections were re-blocked as described above and incubated overnight in rabbit VGLUT2 antibody (Fremeau et al., 2001; 1:1000). The sections were then rinsed $3 \times 5 \mathrm{~min}$ and incubated in goat anti-rabbit coupled to Cy3 (1:500; Molecular Probes). Following rinses in PBS the sections were mounted with Fluoromount G.

Stained sections were examined in a Zeiss confocal unit Pascal 5 LSM mounted on a Zeiss Axioplan 2 microscope. z stack scans were performed using a X63 oil immersion lens. Pinhole, adjusted around 1 area unit, was optimized for each laser wavelength (488 $\mathrm{nm}$ and $568 \mathrm{~nm}$ ) in order to get the same optical slice for each wavelength. There was no gap in between each picture scanned. The same settings were kept for each z stack scans. Seven z stack scans were performed in lamina IX and seven others were acquired from lamina III-IV. Double stained terminals were determined in three dimensions to ensure that the yellow staining observed was not due to a close overlap between 2 terminals stained with different dyes. Double stained terminals were counted for each z stack scans. Because the distance scanned in the $\mathrm{z}$ varied for each $\mathrm{z}$ stack scans, the number of double stained terminals was related to the volume (i.e., optical slices of identical volume; Table 4) of tissue scanned.

\section{RESULTS}


In the descriptions below, the delineations of spinal cord laminae follows those described by Molander et al. (1984, 1989). Laminar boundaries were inferred by direct comparison of the labeled sections with the published drawings and micrographs in the cited papers. The delineation between lamina II and III was aided by examination of the sections with dark field optics.

Light microscopic analysis at high magnification revealed that VGLUT1 immunolabeled varicosities in the spinal cord varied largely in size (Fig. 1 A, C, E; Table 2). In contrast, VGLUT2 immunolabeled varicosities displayed a relatively uniform small size throughout the spinal gray matter (Fig. 1 B, D, F; Table 3). Measurements of VGLUT1 varicosities in the different laminae indicated the presence of at least two different populations, one of small $(\approx 1-2 \mu \mathrm{m})$ and another of medium-sized $(\approx 2-4 \mu \mathrm{m})$ to large $(\approx 4-8 \mu \mathrm{m})$ varicosities (Fig. 2$)$. Nerve fibers connecting labeled varicosities were also discernable in most regions of the spinal gray matter in the VGLUT1 immunolabeled sections. In some cases, a single VGLUT1 immunolabeled fiber harbored up to ten varicosities. Although a fiber harboring mainly medium-sized to large varicosities occasionally also displayed a relatively small varicosity, and vice versa, most varicosities on a single fiber were of the same size range.

\section{Distribution of VGLUT1 immunolabeling}

VGLUT1 immunolabeled varicosities were present in almost all parts of the spinal gray matter, although in different densities and with different appearance (Fig. $3 \mathrm{~A}_{1}, \mathrm{~B}_{1}, \mathrm{C}_{1}, \mathrm{D}_{1}$ ). Dense clustering of medium-sized VGLUT1 immunolabeled varicosities was evident in lamina III-IV and extending into the inner third of lamina II (Figs. $3 \mathrm{~A}_{1}, \mathrm{~B}_{1}, \mathrm{C}_{1}, \mathrm{D}_{1}, 4 \mathrm{~A}_{1}$ ). In the medial part of the dorsal horn, the high density of medium-sized varicosities extended ventrally into lamina $\mathrm{V}$ and, in $\mathrm{C} 6$ and L4, lamina VI (Figs. $3 \mathrm{~A}_{1}, \mathrm{~B}_{1}, \mathrm{C}_{1}, \mathrm{D}_{1}, 4 \mathrm{~B}_{1}$ ). In the spinal enlargements, this labeling was concentrated in the central/medial parts of lamina $\mathrm{V}$ VI, while the reticulated lateral parts, and usually also the more narrow medialmost parts, contained lower densities of labeled varicosities (Fig. $3 \mathrm{~B}_{1}, \mathrm{D}_{1}$ ). In the intermediate zone and ventral horn, medium-sized to large VGLUT1 varicosities were scattered at low to moderate density throughout most of lamina VII, whereas only few such varicosities were evident in lamina VIII (Figs. 1 C, 2, $3 \mathrm{~A}_{1}, \mathrm{~B}_{1}, \mathrm{C}_{1}, \mathrm{D}_{1}, 5 \mathrm{~A}_{1}$ ). Lamina IX contained a moderate density of medium-sized to large VGLUT1 varicosities (Figs. 1 E, 5 B 1 ). 
Small VGLUT1 immunolabeled varicosities were present in most areas of the spinal gray matter. In the superficial dorsal horn, small VGLUT1 varicosities were present at the highest density in lamina I and in the outer third of lamina II, whereas usually only very sparse VGLUT1 immunolabeling was present in the central third of lamina II (Figs. $1 \mathrm{~A}, 3 \mathrm{~A}_{1}, \mathrm{~B}_{1}$, $\mathrm{C}_{1}, \mathrm{D}_{1}$ ). However, in segments C6 and L4 small VGLUT1 varicosities were scattered at about equal density throughout the dorsoventral extent of the medial half of laminae I-II, whereas the lateral half displayed a distribution pattern similar to that of the whole mediolateral extent of laminae I-II at C2 and T8 (Fig. $4 \mathrm{~A}_{1}$ ). Small VGLUT1 varicosities were also present in lamina III-VI (Fig. 2), although their density was difficult to appreciate due to the high density of strongly stained medium-sized to large varicosities. A sparse network of thin fibers with small VGLUT1 varicosities was evident throughout most parts of laminae VII and VIII (Figs. $1 \mathrm{C}, 2,5 \mathrm{~A}_{1}$ ). However, this network ended at the border of lamina IX, in which VGLUT1 immunolabeling was clearly dominated by medium-sized to large varicosities (Figs. $1 \mathrm{E}, 2,5 \mathrm{~B}_{1}$ ). Lamina $\mathrm{X}$ contained relatively sparse small and some large VGLUT1 immunolabeled varicosities (Figs. $3 \mathrm{~A}_{1}, \mathrm{~B}_{1}, \mathrm{C}_{1}, \mathrm{D}_{1}, 7 \mathrm{~B}_{1}$ ).

VGLUT1 immunolabeled varicosities were also present in certain special spinal cord nuclei at different levels. In segment $\mathrm{C} 2$ (Fig. $3 \mathrm{~A}_{1}$ ), a high density of mostly medium-sized to large varicosities was evident in the central cervical nucleus (Fig. $6 \mathrm{~A}_{1}$ ). The internal basilar nucleus contained a high density of both small and large VGLUT1 varicosities (Fig. $6 \mathrm{~B}_{1}$ ). Dense VGLUT1 immunolabeling was also noted around scattered neurons in the gracile fasciculus in segments $\mathrm{C} 1$ and $\mathrm{C} 2$ (Fig. $3 \mathrm{~A}_{1}$ ). In the lateral spinal nucleus, located in the white matter ventral to the lateral part of the dorsal horn throughout the spinal cord (Fig. $3 \mathrm{~A}_{1}$, $\mathrm{B}_{1}, \mathrm{C}_{1}, \mathrm{D}_{1}$ ), a relatively low density of small VGLUT1 immunolabeled varicosities were present (Fig. $6 \mathrm{C}_{1}$ ). However, no or only very sparse VGLUT1 immunolabeling was seen in the adjacent lateral cervical nucleus in segments C1-C3 (Figs. $3 \mathrm{~A}_{1}, 6 \mathrm{C}_{1}$ ). In segments T8 and T9, the intermediolateral nucleus (Fig. $3 \mathrm{C}_{1}$ ) was not clearly defined in all sections. However, in many of the sections a small region with a location corresponding to that of the intermediolateral nucleus was virtually devoid of VGLUT1 immunolabeling (Fig. 7 A ; cf. Stornetta et al., 2002; Nakamura et al., 2005). Dense VGLUT1 immunolabeling, composed of mainly medium-sized to large varicosities, was present in the column of Clarke (Fig. $7 \mathrm{~B}_{1}$; cf. Alvarez et al., 2004). In segments C6 and L4, a cluster of medium-sized to large VGLUT1 immunolabeled varicosities was in many sections evident in the medial-most part of lamina VII at a location corresponding to that of the intermediomedial nucleus (Fig. $3 \mathrm{~B}_{1}, \mathrm{D}_{1}$ ). A similar pattern of labeling may also be present in segments $\mathrm{C} 2$ and $\mathrm{T} 8$, although it was often 
not clearly separable from the dense labeling in the central cervical nucleus and in the column of Clarke, respectively.

In the white matter, the most conspicuous VGLUT1 immunolabeling was that of thin fibers in the pyramidal tract in the ventral part of the dorsal columns (Figs. $3 \mathrm{~A}_{1}, \mathrm{~B}_{1}, \mathrm{C}_{1}, \mathrm{D}_{1}, 6$ $\mathrm{B}_{1}, 7 \mathrm{~B}_{1}$ ). Also large axons in the rest of the dorsal column, especially in the gracile fasciculus at rostral levels (Fig. $3 \mathrm{~A}_{1}$ ), had a faint labeling that exceeded that seen in most axons in the lateral and ventral funiculi. Sparse small VGLUT1 immunolabeled varicosities were also present in bundles extending from the spinal gray matter into the lateral and ventral funiculi.

\section{Distribution of VGLUT2 immunolabeling and comparison with VGLUT1}

VGLUT2 immunolabeling was present in all areas of the spinal gray matter (Fig. $1 \mathrm{~A}_{2}, \mathrm{~B}_{2}, \mathrm{C}_{2}$, $\mathrm{D}_{2}$ ). Although the labeling densities varied between different areas, the differences were in general less than those in VGLUT1 immunolabeled sections. Except for in a few areas of the spinal gray matter, the density of VGLUT2 immunolabeled puncta exceeded that of VGLUT1 immunolabeled puncta. At high magnification, VGLUT2 immunolabeling was clearly dominated by relatively small varicosities (similar in size to the small VGLUT1 immunolabeled varicosities; Figs. 1, 2; Tables 2,3), although some larger, usually faintly labeled, varicosities were evident in some areas, e.g. laminae III-IV, lamina IX and the column of Clarke. Only small differences in the average size of VGLUT2 immunolabeled varicosities were noted between different areas of the spinal gray matter (Table 3).

Generally, areas with sparse VGLUT1 immunolabeled large varicosities were the areas that contained the highest densities of VGLUT2 immunolabeling (Fig. $3 \mathrm{~A}_{2}, \mathrm{~B}_{2}, \mathrm{C}_{2}, \mathrm{D}_{2}$ ). In the dorsal horn, relatively sparse VGLUT2 immunolabeling was present in laminae III-IV and in the central/medial parts of laminae V-VI, whereas high densities of VGLUT2 labeling were evident in the superficial dorsal horn, especially in lamina I and the outer part of lamina II (Figs. $1 \mathrm{~B}, 4 \mathrm{~A}_{2}$ ), and in the lateral parts of laminae V-VI (Fig. $4 \mathrm{~B}_{2}$ ). In the intermediate zone and ventral horn, displaying overall high VGLUT2 labeling densities (Figs. 1 D, F, $3 \mathrm{~A}_{2}, \mathrm{~B}_{2}$, $\mathrm{C}_{2}, \mathrm{D}_{2}$ ), slightly higher labeling densities were seen in lamina VIII as compared to laminae VII and IX (Fig. $5 \mathrm{~A}_{2}, \mathrm{~B}_{2}$ ). These differences in VGLUT2 labeling density between laminae VII-IX were more apparent in the spinal enlargements (Fig. $3 \mathrm{~B}_{2}, \mathrm{D}_{2}$ ). In segments C2 (Fig. 3 $\mathrm{A}_{2}$ ) and T8 (Fig. $3 \mathrm{C}_{2}$ ) VGLUT2 immunolabeling density in the ventral spinal gray matter appeared homogeneous except for a slightly lower labeling density in lamina IX. 
In the central cervical nucleus, the internal basilar nucleus and the column of Clarke, all containing high densities of VGLUT1 immunolabeling, only sparse VGLUT2 immunolabeling were present (Figs. 6 A, B, 7 B). Both the lateral spinal and lateral cervical nuclei contained relatively high densities of VGLUT2 immunolabeled varicosities (Fig. $\left.6 \mathrm{C}_{2}\right)$. In segments T8 and T9, VGLUT2 immunolabeling density in the intermediolateral nucleus was not appreciably different from that in the adjacent areas of laminae V and VII (Figs. $3 \mathrm{C}_{2}$, $7 \mathrm{~A}_{2}$ ). Lamina X contained a relatively high density of mostly small VGLUT2 immunolabeled varicosities (Figs. $3 \mathrm{~A}_{2}, \mathrm{~B}_{2}, \mathrm{C}_{2}, \mathrm{D}_{2}, 7 \mathrm{~B}_{2}$ ).

Anterograde $\mathrm{CTb}$ labeling of spinocervical tract varicosities in the lateral cervical nucleus and simultaneous immunolabeling for VGLUT1 or VGLUT2 (Fig. 8), demonstrated that virtually all spinocervical tract varicosities (97.4-98.1\%) were immunoreactive for VGLUT2 $(n=156-165$ in each of three rats). In contrast, only 6 out of 480 examined spinocervical tract varicosities $(1.3 \%)$ were judged to contain immunoreactivity for VGLUT1. However, immunofluorescence for VGLUT1 in the few immunopositive varicosities was only slightly above background and similar to or fainter than that evident in the most sparsely labeled VGLUT2-postive spinocervical tract varicosities.

Except for faint background staining, no labeling similar to that of the pyramidal tract in VGLUT1 immunolabeled sections was evident in the spinal white matter of VGLUT2 immunolabeled sections. However, the bundles extending from the spinal gray matter into the lateral and ventral funiculi, which contained only sparse small VGLUT1 immunolabeled varicosities, harbored a relatively high density of small VGLUT2 immunolabeled varicosities (Figs. 3, 5 B). The presence of such varicosities often extended almost all the way to the spinal cord surface.

\section{Co-localization of VGLUT1 and VGLUT2}

Examination of sections immunofluorescence-stained for both VGLUT1 and VGLUT2 demonstrated a distribution pattern of the transporters essentially identical to that evident in immunoperoxidase stained sections (Fig. 9; cf. Fig. 3A). The double staining performed with antibodies raised in the same host species (see Material and Methods) gave the same results as the double staining using antibodies raised in different host species. Control sections incubated without primary antibodies showed a faint, diffuse and homogeneous background (not shown). 
Analysis of double stained sections with confocal microscopy demonstrated that the majority of immunolabeled varicosities in the spinal cord were labeled for either VGLUT1 or VGLUT2. However, in both laminae III-IV and lamina IX, a proportion of varicosities was labeled for both transporters (Fig. 9C). The density of double-labeled varicosities was significantly higher in laminae III-IV than in lamina IX (Table 4). Reconstruction of double labeled terminals at high magnification by serial confocal scans in the $\mathrm{z}$ axis, without gap in between the scans, demonstrated colocalization of the VGLUT1 and VGLUT2 in the xy, xz, yz axes (Fig. 9C, inset), excluding possible false colocalization due to close apposition of structures differently stained.

\section{DISCUSSION}

The present findings on the spinal distribution of VGLUT1 and VGLUT2 generally concur with those in earlier brief descriptions (Varoqui et al., 2002; Kaneko et al., 2002) and with those in more recent analyses of select levels and fiber systems (Todd et al., 2003; Li et al., 2003; Oliveira et al., 2003; Landry et al., 2004; Alvarez et al., 2004) and adds to previous findings by providing detailed descriptions of the appearance and distributions of VGLUT1 and VGLUT2 immunolabeled varicosities at several different spinal levels. Although some differences were noted, the laminar distribution pattern of VGLUT1 was found to be similar at all spinal levels examined, as was that of VGLUT2. Areas known to receive abundant input from large caliber primary afferent fibers, i.e. the central cervical nucleus, the internal basilar nucleus and the spinal extension of the gracile nucleus, were found to contain high densities of medium-sized to large VGLUT1-immunoreactive varicosities, as previously and presently demonstrated for the deep dorsal horn, laminae VII and IX and the column of Clarke.

Laminae I-II contain a moderate to sparse density of mainly small VGLUT1-immunoreactive varicosities, with mediolateral differences in distribution patterns in the enlargements not previously recognized. A proportion of these varicosities most likely originate in the corticospinal tract, although their distribution indicates also other origins. Further, the lateral cervical nucleus contained a high density of VGLUT2- immunoreactive varicosities but was virtually free of VGLUT1-immunoreactive varicosities. Consequently, virtually all anterogradely labeled spinocervical tract terminations in the lateral cervical nucleus were immunoreactive for VGLUT2. 


\section{Origin of immunolabeled terminals}

VGLUT1. There is now abundant evidence that VGLUT1 is present in large diameter low threshold skin and muscle primary afferent terminals in the spinal cord, corroborating extensive electrophysiological/pharmacological and glutamate immunogold labeling data supporting a transmitter role of glutamate in such terminals (e.g. Salt and Hill, 1983; Jahr and Yoshioka, 1986; Schouenborg and Sjölund, 1986; Gerber and Randic, 1989; Walmsley and Nicol, 1991; Maxwell et al., 1990a; Broman et al., 1993; Maxwell et al., 1993; Broman and Ådahl, 1994; Valtschanoff et al., 1994; Örnung et al., 1995; Larsson et al., 2001; Ragnarson et al., 2003). Dorsal rhizotomy results in significant depletion of large VGLUT1 immunolabeled varicosities in the ventral horn and deep dorsal horn (Li et al., 2003; Oliveira et al., 2003; Alvarez et al., 2004; Wu et al., 2004), and essentially all primary afferent terminals in these regions labeled by choleragenoid (Todd et al., 2003), or for specific antigens identifying such terminals (Alvarez et al., 2004), are immunopositive for VGLUT1. The presence of VGLUT1 in these terminals is also supported by extensive expression of VGLUT1 mRNA in numerous large neurons in dorsal root ganglia (Oliveira et al., 2003). In conclusion, most of the medium-sized to large VGLUT1 immunolabeled varicosities detected in laminae II-VII and IX presumably originate from low threshold skin or muscle primary afferent fibers. The same is most likely also the case for the large VGLUT1 immunoreactive terminals in the central cervical nucleus, in the column of Clarke, in the internal basilar nucleus (rostrally continuous with the cuneate nucleus; Molander et al., 1989) and around the scattered neurons in the gracile fasciculus at rostral spinal cord levels, areas which all receive abundant input by such afferents.

A proportion of primary afferent terminals in lamina III-IV (Todd et al., 2003; Alvarez et al., 2004) and possibly also in the ventral horn (Alvarez et al., 2004; but see Todd et al., 2003; Oliveira et al., 2003) co-contains VGLUT1 and VGLUT2. The present observation that VGLUT1 and VGLUT2 co-localize in a proportion of varicosities in laminae III-IV and lamina IX, further support the notion that some primary afferent terminals in both the deep dorsal horn and the ventral horn express VGLUT2 in addition to VGLUT1. In the rodent brain, an extensive expression of VGLUT2 is evident already at birth (Boulland et al., 2004; Fremeau et al., 2004a). In contrast, expression of VGLUT1 is sparse at birth and then increases progressively during postnatal development. In many regions, VGLUT2 is downregulated in parallel with an increase in VGLUT1 expression. It is thus tempting to speculate 
that the expression pattern in large caliber primary afferents in adult rats, i.e. sparse presence of VGLUT2 in fibers primarily expressing VGLUT1, reflects developmental changes. A likely scenario in light of the above observations would be an initial high VGLUT2 expression and absent or low VGLUT1 expression in these fibers that, during the course of development, is replaced by a high VGLUT1 expression and sparse expression of VGLUT2, similar to the change noted in cerebellar parallel fibers (Miyazaki et al., 2003). Such a scenario would be concordant with findings in VGLUT1 knockout mice, which display no gross phenotype abnormalities at birth but gradually develops neurological defects from 2-3 weeks after birth (Fremeau et al., 2004a). However, whether developmental changes in VGLUT expression occur also in the spinal cord remains to be demonstrated.

Another important source for VGLUT1 immunolabeled varicosities in the spinal cord is the pyramidal tract. We detected clear VGLUT1 immunolabeling, but no VGLUT2 immunolabeling, in pyramidal tract axons in the ventral part of the dorsal column (see also Alvarez et al., 2004). Further, the distribution pattern of small VGLUT1 immunolabeled varicosities in the spinal cord, i.e. their presence in most laminae though sparse in lamina IX in comparison to laminae VII-VIII, and in segments C6 and L4 more extensive throughout the medial half than the lateral half of lamina I-II, closely resembles the distribution of anterogradely labeled corticospinal tract axon terminals in rats and cats (Cheema et al., 1984; Casale et al., 1988; Liang et al., 1991; Valtschanoff et al., 1993). VGLUT1 mRNA is also highly expressed in the deep layers of the cerebral cortex where corticospinal tract neurons are located (Ni et al., 1994; Fremeau et al., 2001; Herzog et al., 2001). Thus, it appears likely that at least a sizable proportion of small VGLUT1 varicosities originate in the cerebral cortex.

However, only a proportion of the small VGLUT1 varicosities in laminae I-II has a distribution equivalent to that observed for corticospinal terminations. The corticospinal tract terminations in laminae I-II locate primarily in the medial part of the dorsal horn in the spinal enlargements, corresponding somatotopically to the distal parts of the limbs (Casale et al., 1988). Thus, the small VGLUT1 varicosities, present at low to moderate density throughout the mediolateral and rostrocaudal extent of laminae I and IIo, presumably mainly have another origin. Alvarez et al. (2004) detected a significant depletion of VGLUT1 in lamina I in rhizotomized rats, thus indicating a primary afferent origin of at least some of the VGLUT1 immunolabeled terminations at this location. A possible explanation for this labeling pattern would be an association of VGLUT1 specifically to large dense core vesicles in a population of peptidergic primary afferent terminals, as demonstrated by Alvarez et al. (2004). 
Alternatively, a subpopulation of primary afferents in laminae I-II not identified by the labeling techniques or criteria used in previous studies principally express VGLUT1.

The detection of VGLUT1 immunolabeling in pyramidal tract axons, and to some extent also in axons of the dorsal column, suggests that some axons may harbor significant amounts of VGLUT1-containing vesicles presumably under transport towards the axon terminals. In contrast, we found no clear VGLUT2 immunolabeling of axons in the spinal white matter, indicating absence or low levels of this antigen. Although this possibly could be explained by different detection sensitivities (i.e., a higher sensitivity of the VGLUT1 antisera in detecting low levels of antigen), it may also reflect a true difference in the levels of these antigens in axons, possibly related to differences in membrane trafficking between VGLUT1 and VGLUT2 (Fremeau et al., 2004a).

An early study indicated sparse or absent expression of VGLUT1 mRNA in the spinal cord (Aihara et al., 2000). However, two recent studies (Kullander et al., 2003; Oliveira et al., 2003) detected small populations of VGLUT1 mRNA expressing neurons located dorsal and lateral to the central canal. The further identity and connections of these neurons are unknown, but if their axons ramify in the spinal cord they are likely to contribute to some of the VGLUT1 immunolabeled varicosities detected.

VGLUT2. In most previous studies, dorsal rhizotomies are reported to result in minimal or no appreciable depletion of VGLUT2 immunolabeling in the spinal cord (Oliveira et al., 2003; Alvarez et al., 2004; but see Li et al., 2003). However, most varicosities in lamina I labeled with transganglionic transport of $\mathrm{CTb}$, most likely A $\delta$ fiber terminals, contain VGLUT2 (Todd et al., 2003). Using immunofluorescent labeling for VGLUT2 in combination with markers for primary afferent terminals, Todd et al. (2003) and Morris et al. (2005) also detected sparse VGLUT2 immunolabeling in some primary afferent terminals in lamina II. Using electron microscopic immunogold labeling, Alvarez et al. (2004) detected significant but relatively low levels of VGLUT2 in most presumed C-fiber primary afferent terminals in lamina II. Thus, it appears that most primary afferent terminals in the superficial dorsal horn contain VGLUT2, although at levels lower than those in terminals originating from dorsal horn local circuit neurons (Todd et al., 2003). This presumably explains why their disappearance is usually undetected following dorsal rhizotomy. Primary afferent terminals in lamina II contain high levels of glutamate (DeBiasi and Rustioni, 1988; Maxwell et al., 1990b; Broman et al., 1993; Broman and Ådahl, 1994; Valtschanoff et al., 1994; Larsson et al., 2001) and there is abundant physiological/pharmacological evidence that support 
glutamate as a fast primary afferent neurotransmitter in such terminals (e.g. Rustioni and Weinberg, 1989, Aanonsen et al., 1990; Broman, 1994; Broman et al., 2000). Whether the relatively low VGLUT2-levels in primary afferent $\mathrm{C}$-fiber terminals are sufficient to sustain the release of glutamate from these terminals or if other mechanisms are involved remains to be elucidated.

VGLUT2 mRNA is expressed in neurons scattered throughout large parts of the spinal gray matter, including sparsely labeled neurons in the superficial dorsal horn (Kullander et al., 2003; Oliveira et al., 2003; Landry et al., 2004; Herzog et al., 2004). Consequently, Todd et al. (2003) detected VGLUT2 immunolabeling in most of the superficial dorsal horn terminals that originate from certain populations of excitatory local circuit neurons. Some of the VGLUT2 expressing neurons in the ventral horn are suggested to be an excitatory component in the spinal central pattern generator (Kullander et al., 2003), and axonal varicosities from a proportion of commissural interneurons in the ventral horn are immunolabeled for VGLUT2 (Bannatyne et al., 2003). As a substantial population of spinal cord neurons express VGLUT2 mRNA, it appears likely that many of the VGLUT2 immunolabeled varicosities in laminae VII-IX originate from excitatory spinal cord local circuit and propriospinal neurons relaying different kinds of reflex activity or descending motor commands. Further, a proportion of VGLUT2 immunolabeled varicosities in the spinal cord are likely to originate from supraspinal sources other than the corticospinal tract, although positive evidence for the presence of VGLUT2 in such terminals are yet sparse. However, neurons in the rostral ventral respiratory group in the medulla oblongata with axons terminating in the cervical ventral horn express VGLUT2 mRNA and contain VGLUT2 in their terminals (Stornetta et al., 2003; Yokota et al., 2003), as do terminals in the phrenic nucleus originating from neurons in the Kölliker-Fuse nucleus (Yokota et al., 2003). Further, neurons in the rostral ventrolateral medulla projecting to the spinal cord express VGLUT2 mRNA (Stornetta et al., 2002).

Recently, Landry et al. (2004) and Herzog et al. (2004) demonstrated expression of VGLUT1 and VGLUT2 mRNA in motoneurons. Herzog et al. (2004) also demonstrated that some motoneuron axon collaterals were VGLUT2 immunopositive and some of these contacted calbindin immunolabeled neurons (presumably Renshaw cells). Thus, some VGLUT2 immunolabeled varicosities in the ventral horn may originate from motoneurons.

The lateral cervical nucleus was found to be virtually devoid of VGLUT1 immunolabeling but to contain dense labeling for VGLUT2. Neurons in the lateral cervical nucleus relay sensory information from spinocervical tract neurons in the ipsilateral dorsal horn to among others the contralateral ventral posterior lateral nucleus of the thalamus 
(Giesler et al., 1988; Zhang et al., 2002). Previous studies in cats have demonstrated that terminals of the spinocervical tract contain high levels of glutamate associated with synaptic vesicles but low levels of glutamine (Broman et al., 1990; Kechagias and Broman, 1994, 1995), making strong arguments for glutamate as a spinocervical tract neurotransmitter in cats. Our present demonstration that virtually all spinocervical tract terminations in rats are immunoreactive for VGLUT2 strongly support glutamate as a spinocervical tract neurotransmitter also in rats, and demonstrate that vesicular accumulation of glutamate in spinocervical tract terminals is sustained primarily if not exclusively by VGLUT2.

\section{Functional considerations}

Based on the presence of either VGLUT1 or VGLUT2 in select nerve terminal populations in primarily the hippocampus and the cerebellum (e.g. cerebellar climbing fibers, expressing VGLUT2, and parallel fibers, expressing VGLUT1) a role in determining release probability for the VGLUTs has been proposed (Fremeau et al., 2001; Varoqui et al., 2002). Thus, VGLUT1 is expressed in terminals with low probability of release and activity-dependent potentiation, whereas VGLUT2 is expressed in terminals displaying high probability of release and high-fidelity neurotransmission. The explanation for such a difference is not clear, but may be related to differences in the cytoplasmic C-termini of VGLUT1 and VGLUT2, resulting in different protein-protein interactions of the transporters that could affect the mode and rate of synaptic vesicle recycling (Fremeau et al., 2004a,b). For example, synaptic vesicles in cerebellar climbing fiber and parallel fiber terminals associate with different $G$ protein subunits (Pahner et al., 2003).

Most glutamatergic fiber systems in the spinal cord should display high probability of release and high-fidelity neurotransmission due to their use of VGLUT2 as vesicular transporter. This should be the case for most intrinsic glutamatergic neurons, glutamatergic projections from the brainstem and also the spinocervical tract (and presumably also other ascending spinal sensory pathways as judged from the distribution of neurons expressing mRNA for VGLUT1 or VGLUT2; Kullander et al., 2003; Oliveira et al., 2003). The major VGLUT1 immunoreactive fiber systems in the spinal cord, i.e. the corticospinal tract and the large caliber skin and muscle primary afferents, should in contrast form synapses with lower release probability. To our knowledge, detailed studies of release probability in primary afferent synapses are sparse. Ia afferent synapses with motoneurons and dorsal 
spinocerebellar tract neurons have been examined (Redman and Walmsley, 1983; Walmsley et al., 1988; Clamann et al., 1989), and most such synapses appear to have low probabilities of release, thus supporting a correlation between use of VGLUT1 and low release probability. However, a significant proportion of such synapses do display high release probability. Furthermore, the interpretation of data is complicated by the co-expression of VGLUT1 and VGLUT2 in mechanoreceptor afferent terminals (Todd et al., 2003; Oliveira et al., 2003; Alvarez et al., 2004; present study).

Another potentially important issue, so far receiving little attention, is whether the levels of VGLUTs in primary afferent fibers are subject to regulation in a manner similar to the positive or negative effects on peptide expression in dorsal root ganglion neurons evident after peripheral nerve injury or peripheral inflammation (Willis and Coggeshall, 2004). Hughes et al. (2004) demonstrated a depletion of VGLUT1 in myelinated primary afferent terminations in the deep dorsal horn and lamina IX following a lesion to the sciatic nerve. Whether injury to peripheral nerves and peripheral inflammation also induces positive or negative effects on VGLUT expression in thin caliber primary afferents is at present unknown. If such changes occur they may be of importance for changes in pain perception, considering the impact changes in VGLUT expression could have on vesicular filling and quantal size and therefore on synaptic strength (Wilson et al., 2005).

\section{LITERATURE CITED}

Aanonsen LM, Lei S, Wilcox GL. 1990. Excitatory amino acid receptors and nociceptive neurotransmission in rat spinal cord. Pain 4:309-321.

Aihara Y, Mashima H, Onda H, Hisano S, Kasuya H, Hori T, Yamada S, Tomura H, Yamada Y, Inoue I, Kojima I, Takeda J. 2000. Molecular cloning of a novel brain-type $\mathrm{Na}^{+}$-dependent inorganic phosphate cotransporter. J Neurochem 74:2622-2625.

Alvarez FJ, Villalba RM, Zerda R, Schneider SP. 2004. Vesicular glutamate transporters in the spinal cord, with special reference to sensory primary afferent synapses. J Comp Neurol 472:257-280. 
Bannatyne BA, Edgley SA, Hammar I, Jankowska E, Maxwell DJ. 2003. Networks of inhibitory and excitatory commissural interneurons mediating crossed reticulospinal actions. Eur J Neurosci 18:2273-2284.

Baughman RW, Gilbert CD. 1980. Aspartate and glutamate as possible neurotransmitters of cells in layer 6 of the visual cortex. Nature 287:848-850.

Bellocchio EE, Hu H, Pohorille A, Chan J, Pickel VM, Edwards RH. 1998. The localization of the brain-specific inorganic phosphate transporter suggests a specific presynaptic role in glutamatergic transmission. J Neurosci 18:8648-8659.

Bellocchio EE, Reimer RJ, Fremeau RT Jr, Edwards RH. 2000. Uptake of glutamate into synaptic vesicles by an inorganic phosphate transporter. Science 289:957-960.

Boulland JL, Osen KK, Levy LM, Danbolt NC, Edwards RH, Storm-Mathisen J, Chaudhry FA. 2002. Cell-specific expression of the glutamine transporter SN1 suggests differences in dependence on the glutamine cycle. Eur J Neurosci 15:1615-1631.

Boulland JL, Qureshi T, Seal RP, Rafiki A, Gundersen V, Bergersen LH, Fremeau RT Jr, Edwards RH, Storm-Mathisen J, Chaudhry FA. 2004. Expression of the vesicular glutamate transporters during development indicates the widespread corelease of multiple neurotransmitters. J Comp Neurol 480:264-280.

Broman J, Ådahl F. 1994. Evidence for vesicular storage of glutamate in primary afferent terminals. Neuroreport 5:1801-1804.

Broman J, Westman J, Ottersen OP. 1990. Ascending afferents to the lateral cervical nucleus are enriched in glutamate-like immunoreactivity: a combined anterograde transportimmunogold study in the cat. Brain Res 520:178-191.

Broman J, Anderson S, Ottersen OP. 1993. Enrichment of glutamate-like immunoreactivity in primary afferent terminals throughout the spinal cord dorsal horn. Eur J Neurosci 5:10501061. 
Broman J, Hassel B, Rinvik E, Ottersen OP. 2000. Biochemistry and anatomy of transmitter glutamate. In: Ottersen OP, Storm-Mathisen J, editors. Handbook of chemical neuroanatomy, vol. 18: Glutamate. Amsterdam: Elsevier. p 1-44.

Broman J, Rinvik E, Sassoe-Pognetto M, Khalkhali Shandiz H, Ottersen OP. 2004.

Glutamate. In: Paxinos G, editor. The rat nervous system, third edition. Amsterdam: Elsevier. p 1269-1292.

Casale EJ, Light AR, Rustioni A. 1988. Direct projection of the corticospinal tract to the superficial laminae of the spinal cord in the rat. J Comp Neurol 278:275-286.

Cheema SS, Rustioni A, Whitsel BL. 1984. Light and electron microscopic evidence for a direct corticospinal projection to superficial laminae of the dorsal horn in cats and monkeys. $\mathrm{J}$ Comp Neurol 225:276-290.

Clamann HP, Mathis J, Luscher HR. 1989. Variance analysis of excitatory postsynaptic potentials in cat spinal motoneurons during posttetanic potentiation. J Neurophysiol 61:403416.

Curtis DR, Watkins JC. 1960. The excitation and depression of spinal neurones by structurally related amino acids. J Neurochem 6:117-141.

DeBiasi S, Rustioni A. 1988. Glutamate and substance P coexist in primary afferent terminals in the superficial laminae of spinal cord. Proc Natl Acad Sci U S A 85:7820-7824.

Fonnum F. 1984. Glutamate: a neurotransmitter in mammalian brain. J Neurochem 42:1-11.

Franzusoff A, Redding K, Crosby J, Fuller RS, Schekman R. 1991. Localization of components involved in protein transport and processing through the yeast Golgi apparatus. J Cell Biol 112:27-37.

Fremeau RT Jr, Troyer MD, Pahner I, Nygaard GO, Tran CH, Reimer RJ, Bellocchio EE, Fortin D, Storm-Mathisen J, Edwards RH. 2001. The expression of vesicular glutamate transporters defines two classes of excitatory synapse. Neuron 31:247-260. 
Fremeau RT Jr, Burman J, Qureshi T, Tran CH, Proctor J, Johnson J, Zhang H, Sulzer D, Copenhagen DR, Storm-Mathisen J, Reimer RJ, Chaudhry FA, Edwards RH. 2002. The identification of vesicular glutamate transporter 3 suggests novel modes of signaling by glutamate. Proc Natl Acad Sci U S A 99:14488-14493.

Fremeau RT Jr, Kam K, Qureshi T, Johnson J, Copenhagen DR, Storm-Mathisen J, Chaudhry F, Nicoll RA, Edwards RH. 2004a. Vesicular glutamate transporters 1 and 2 target to functionally distinct synaptic release sites. Science 304:1815-1819.

Fremeau RT Jr, Voglmaier S, Seal RP, Edwards RH. 2004b. VGLUTs define subsets of excitatory neurons and suggest novel roles for glutamate. Trends Neurosci 27:98-103.

Fykse EM, Christensen H, Fonnum F. 1989. Comparison of the properties of gammaaminobutyric acid and L-glutamate uptake into synaptic vesicles isolated from rat brain. $\mathrm{J}$ Neurochem 52:946-951.

Gerber G, Randic M. 1989. Excitatory amino acid-mediated components of synaptically evoked input from dorsal roots to deep dorsal horn neurons in the rat spinal cord slice. Neurosci Lett 106:211-219.

Giesler GJ Jr, Björkeland M, Xu Q, Grant G. 1988. Organization of the spinocervicothalamic pathway in the rat. J Comp Neurol 268:223-233.

Gras C, Herzog E, Bellenchi GC, Bernard V, Ravassard P, Pohl M, Gasnier B, Giros B, El Mestikawy S. 2002. A third vesicular glutamate transporter expressed by cholinergic and serotoninergic neurons. J Neurosci 22:5442-5451.

Hayashi T. 1954. Effects of sodium glutamate on the nervous system. Keio J Med 3:183-192.

Herzog E, Bellenchi GC, Gras C, Bernard V, Ravassard P, Bedet C, Gasnier B, Giros B, El Mestikawy S. 2001. The existence of a second vesicular glutamate transporter specifies subpopulations of glutamatergic neurons. J Neurosci 21:RC181. 
Herzog E, Landry M, Buhler E, Bouali-Benazzouz R, Legay C, Henderson CE, Nagy F, Dreyfus P, Giros B, El Mestikawy S. 2004. Expression of vesicular glutamate transporters, VGLUT1 and VGLUT2, in cholinergic spinal motoneurons. Eur J Neurosci 20:1752-1760.

Hughes DI, Polgar E, Shehab SAS, Todd AJ. 2004. Peripheral axotomy induces depletion of the vesicular glutamate transporter VGLUT1 in central terminals of myelinated afferent fibers in the rat spinal cord. Brain Res 1017:69-76.

Jahr CE, Yoshioka K. 1986. Ia afferent excitation of motoneurones in the in vitro new-born rat spinal cord is selectively antagonized by kynurenate. J Physiol 370:515-530.

Kaneko T, Fujiyama F, Hioki H. 2002. Immunohistochemical localization of candidates for vesicular glutamate transporters in the rat brain. J Comp Neurol 444:39-62.

Kechagias S, Broman J. 1994. Compartmentation of glutamate and glutamine in the lateral cervical nucleus: further evidence for glutamate as a spinocervical tract neurotransmitter. J Comp Neurol 340:531-540.

Kechagias S, Broman J. 1995. Immunocytochemical evidence for vesicular storage of glutamate in cat spinocervical and cervicothalamic tract terminals. Brain Res 675:316-320.

Krnjevic K. 1986. Amino acid transmitters: 30 years' progress in research. In: Iversen LL, Goodman E, editors. Fast and slow signalling in the nervous system. Oxford: Oxford University Press. p 3-15.

Kullander K, Butt SJ, Lebret JM, Lundfald L, Restrepo CE, Rydström A, Klein R, Kiehn O. 2003. Role of EphA4 and EphrinB3 in local neuronal circuits that control walking. Science 299:1889-1892.

Landry M, Bouali-Benazzouz R, El Mestikawy S, Ravassard P, Nagy F. 2004. Expression of vesicular glutamate transporters in rat lumbar spinal cord, with a note on dorsal root ganglia. J Comp Neurol 468:380-394. 
Larsson M, Persson S, Ottersen OP, Broman J. 2001. Quantitative analysis of immunogold labeling indicates low levels and non-vesicular localization of L-aspartate in rat primary afferent terminals. J Comp Neurol 430:147-159.

Lewis Carl SA, Gillete-Ferguson I, Ferguson DG. 1993. An indirect immunofluorescence procedure for staining the same cryosection with two mouse monoclonal primary antibodies. $\mathbf{J}$ Histochem Cytochem 41:1273-1278.

Li JL, Fujiyama F, Kaneko T, Mizuno N. 2003. Expression of vesicular glutamate transporters, VGluT1 and VGluT2, in axon terminals of nociceptive primary afferent fibers in the superficial layers of the medullary and spinal dorsal horns of the rat. J Comp Neurol 457:236-249.

Liang FY, Moret V, Wiesendanger M, Rouiller EM. 1991. Corticomotoneuronal connections in the rat: evidence from double-labeling of motoneurons and corticospinal axon arborizations. J Comp Neurol 311:356-366.

Maxwell DJ, Christie WM, Ottersen OP, Storm-Mathisen J. 1990a. Terminals of group Ia primary afferent fibres in Clarke's column are enriched with L-glutamate-like immunoreactivity. Brain Res 510:346-350.

Maxwell DJ, Christie WM, Short AD, Storm-Mathisen J, Ottersen OP. 1990b. Central boutons of glomeruli in the spinal cord of the cat are enriched with L-glutamate-like immunoreactivity. Neuroscience 36:83-104.

Maxwell DJ, Christie WM, Brown AG, Ottersen OP, Storm-Mathisen J. 1993. Identified hair follicle afferent boutons in the spinal cord of the cat are enriched with L-glutamate-like immunoreactivity. Brain Res 606:156-161.

Maycox PR, Deckwerth T, Hell JW, Jahn R. 1988. Glutamate uptake by brain synaptic vesicles. Energy dependence of transport and functional reconstitution in proteoliposomes. J Biol Chem 263:15423-15428. 
Miyazaki T, Fukaya M, Shimizu H, Watanabe M. 2003. Subtype switching of vesicular glutamate transporters at parallel fibre-Purkinje cell synapses in developing mouse cerebellum. Eur J Neurosci 17:2563-2572.

Molander C, Xu Q, Grant G. 1984. The cytoarchitectonic organization of the spinal cord in the rat. I. The lower thoracic and lumbosacral cord. J Comp Neurol 230:133-141.

Molander C, Xu Q, Rivero-Melian C, Grant G. 1989. Cytoarchitectonic organization of the spinal cord in the rat: II. The cervical and upper thoracic cord. J Comp Neurol 289:375-385.

Morris JL, König P, Shimizu T, Jobling P, Gibbins IL. 2005. Most peptide-containing sensory neurons lack proteins for exocytotic release and vesicular transport of glutamate. J Comp Neurol 483:1-16.

Naito S, Ueda T. 1985. Characterization of glutamate uptake into synaptic vesicles. J Neurochem 44:99-109.

Nakamura K, Matsumura K, Kobayashi S, Kaneko T. 2005. Sympathetic premotor neurons mediating thermoregulatory functions. Neurosci Res 51:1-8.

Ni B, Rosteck P, Nadi S, Paul S. 1994. Cloning and expression of a cDNA encoding a brainspecific $\mathrm{Na}^{+}$-dependent inorganic phosphate cotransporter. Proc Natl Acad Sci U S A 91:5607-5611.

Oliveira AL, Hydling F, Olsson E, Shi T, Edwards RH, Fujiyama F, Kaneko T, Hökfelt T, Cullheim S, Meister B. 2003. Cellular localization of three vesicular glutamate transporter mRNAs and proteins in rat spinal cord and dorsal root ganglia. Synapse 50:117-129.

Örnung G, Ragnarson B, Grant G, Ottersen OP, Storm-Mathisen J, Ulfhake B. 1995. Ia boutons to $\mathrm{CCN}$ neurones and motoneurones are enriched with glutamate-like immunoreactivity. Neuroreport 6:1975-1980.

Ottersen OP. 1991. Excitatory amino acid neurotransmitters: anatomical systems. In: Meldrum BS, editor. Excitatory amino acid antagonists. London: Blackwell. p 14-35. 
Pahner I, Höltje M, Winter S, Takamori S, Bellocchio EE, Spicher K, Laake P, Nürnberg B, Ottersen OP, Ahnert-Hilger G. 2003. Functional G-protein heterotrimers are associated with vesicles of putative glutamatergic terminals: implications for regulation of transmitter uptake. Mol Cell Neurosci 23:398-413.

Ragnarson B, Örnung G, Grant G, Ottersen OP, Ulfhake B. 2003. Glutamate and AMPA receptor immunoreactivity in Ia synapses with motoneurons and neurons of the central cervical nucleus. Exp Brain Res 149:447-457.

Redman S, Walmsley B. 1983. Amplitude fluctuations in synaptic potentials evoked in cat spinal motoneurones at identified group Ia synapses. J Physiol 343:135-145.

Rustioni A, Weinberg RJ. 1989. The somatosensory system. In: Björklund A, Hökfelt T, Swanson LW, editors. Handbook of chemical neuroanatomy, vol. 7: Integrated systems of the CNS, part II. Amsterdam: Elsevier. p 219-321.

Salt TE, Hill RG. 1983. Neurotransmitter candidates of somatosensory primary afferent fibres. Neuroscience 10:1083-1103.

Schäfer MK, Varoqui H, Defamie N, Weihe E, Erickson JD. 2002. Molecular cloning and functional identification of mouse vesicular glutamate transporter 3 and its expression in subsets of novel excitatory neurons. J Biol Chem 277:50734-50748.

Schouenborg J, Sjölund BH. 1986. First-order nociceptive synapses in rat dorsal horn are blocked by an amino acid antagonist. Brain Res 379:394-398.

Storm-Mathisen J, Leknes AK, Bore AT, Vaaland JL, Edminson P, Haug FM, Ottersen OP. 1983. First visualization of glutamate and GABA in neurones by immunocytochemistry. Nature 301:517-520.

Stornetta RL, Sevigny CP, Schreihofer AM, Rosin DL, Guyenet PG. 2002. Vesicular glutamate transporter DNPI/VGLUT2 mRNA is expressed by both $\mathrm{C} 1$ adrenergic and 
nonaminergic presympathetic vasomotor neurons of the rat medulla. J Comp Neurol 444:207220.

Stornetta RL, Sevigny CP, Guyenet PG. 2003. Inspiratory augmenting bulbospinal neurons express both glutamatergic and enkephalinergic phenotypes. J Comp Neurol 455:113-124.

Streit P. 1980. Selective retrograde labeling indicating the transmitter of neuronal pathways. J Comp Neurol 191:429-463.

Takamori S, Rhee JS, Rosenmund C, Jahn R. 2000. Identification of a vesicular glutamate transporter that defines a glutamatergic phenotype in neurons. Nature 407:189-194.

Takamori S, Malherbe P, Broger C, Jahn R. 2002. Molecular cloning and functional characterization of human vesicular glutamate transporter 3. EMBO Rep 3:798-803.

Todd AJ, Hughes DI, Polgar E, Nagy GG, Mackie M, Ottersen OP, Maxwell DJ. 2003. The expression of vesicular glutamate transporters VGLUT1 and VGLUT2 in neurochemically defined axonal populations in the rat spinal cord with emphasis on the dorsal horn. Eur $\mathrm{J}$ Neurosci 17:13-27.

Valtschanoff JG, Weinberg RJ, Rustioni A. 1993. Amino acid immunoreactivity in corticospinal terminals. Exp Brain Res 93:95-103.

Valtschanoff JG, Phend KD, Bernardi PS, Weinberg RJ, Rustioni A. 1994. Amino acid immunocytochemistry of primary afferent terminals in the rat dorsal horn. J Comp Neurol 346:237-252.

Varoqui H, Schäfer MK, Zhu H, Weihe E, Erickson JD. 2002. Identification of the differentiation-associated $\mathrm{Na}^{+} / \mathrm{PI}$ transporter as a novel vesicular glutamate transporter expressed in a distinct set of glutamatergic synapses. J Neurosci 22:142-155.

Walmsley B, Nicol MJ. 1991. The effects of $\mathrm{Ca}^{2+}, \mathrm{Mg}^{2+}$ and kynurenate on primary afferent synaptic potentials evoked in cat spinal cord neurones in vivo. J Physiol 433:409-420. 
Walmsley B, Edwards FR, Tracey DJ. 1988. Nonuniform release probabilities underlie quantal synaptic transmission at a mammalian excitatory central synapse. J Neurophysiol 60:889-908.

Watkins JC. 1986. Twenty-five years of excitatory amino acid research. The end of the beginning? In: Roberts PJ, Storm-Mathisen J, Bradford HF, editors. Excitatory amino acids. London: Macmillan. p 1-39.

Wessel GM, McClay DR. 1986. Two embryonic, tissue-specific molecules identified by a double-label immunofluorescence technique for monoclonal antibodies. J Histochem Cytochem 34:703-706.

Willis WD Jr, Coggeshall RE. 2004. Sensory mechanisms of the spinal cord, third edition. Volume 1, Primary afferent neurons and the spinal dorsal horn. New York: Kluwer Academic/Plenum Publishers.

Wilson NR, Kang J, Hueske EV, Leung T, Varoqui H, Murnick JG, Erickson JD, Liu G. 2005. Presynaptic regulation of quantal size by the vesicular glutamate transporter VGLUT1. J Neurosci 25:6221-6234.

Winter HC, Ueda T. 1993. Glutamate uptake system in the presynaptic vesicle: glutamic acid analogs as inhibitors and alternate substrates. Neurochem Res 18:79-85.

Wu S-X, Koshimizu Y, Feng Y-P, Okamoto K, Fujiyama F, Hioki H, Li Y-Q, Kaneko T, Mizuno N. 2004. Vesicular glutamate transporter immunoreactivity in the central and peripheral endings of muscle-spindle afferents. Brain Res 1011:247-251.

Yokota S, Tsumori T, Ono K, Yasui Y. 2003. Glutamatergic pathways from the Kölliker-Fuse nucleus to the phrenic nucleus in the rat. Brain Res 995:118-130.

Zhang M, Liu Y, Broman J. 2002. Organization of the ferret lateral cervical nucleus and cervicothalamic tract. Somatosens Motor Res 19:36-48. 


\section{FIGURE LEGENDS}

Fig. 1. High power photomicrographs of VGLUT1 (A,C, E) and VGLUT2 (B, D, F) immunolabeled varicosities in different spinal cord laminae. A is from the lateral edge of the dorsal horn and shows sparse small VGLUT1 varicosities in lamina I and the outer part of lamina II (right) and abundant medium-sized varicosities in lamina III and the inner part of lamina II (left). Lamina VIII contains sparse small VGLUT1 varicosities (C) and lamina IX a moderate density of medium-sized and large varicosities (E). VGLUT2 immunolabeling, present at high density in lamina I-II (B), is composed mainly of small varicosities in all parts of the spinal gray matter (B, D, F; see also Tables 2 and 3). Calibration bar in F (valid for AF), $20 \mu \mathrm{m}$.

Fig. 2. Histograms depicting the size (long diameter) distribution of VGLUT1 immunolabeled varicosities in different laminae in the spinal cord segment L4. Bottom histogram shows the combined size distribution of varicosities pooled from all laminae. A sum of two logGaussian distributions (which are shown superimposed on the histogram) showed a significantly better fit to the size distribution than did a single log-Gaussian distribution (not shown; $\mathrm{p}<0.0001)$.

Fig. 3. Low power photomicrographs of adjacent spinal cord sections from segments $\mathrm{C} 2$ (A), C6 (B), T8 (C) and L4 (D) immunolabeled for VGLUT1 $\left(\mathrm{A}_{1}, \mathrm{~B}_{1}, \mathrm{C}_{1}, \mathrm{D}_{1}\right)$ or VGLUT2 $\left(\mathrm{A}_{2}, \mathrm{~B}_{2}\right.$, $\mathrm{C}_{2}, \mathrm{D}_{2}$ ). Arrowheads in $\mathrm{B}_{1}$ and $\mathrm{D}_{1}$ point at clusters of labeled varicosities in the medialmost part lamina VII. CC, column of Clarke; $\mathrm{CeCv}$, central cervical nucleus; gr, gracile fasciculus; IBN, internal basilar nucleus; IML, intermediolateral nucleus; LCN, lateral cervical nucleus; LSN, lateral spinal nucleus; pt, pyramidal tract. Calibration bars in B2 and D2 (valid for all photomicrographs), $500 \mu \mathrm{m}$.

Fig. 4. Photomicrographs showing details of VGLUT1 $\left(A_{1}, B_{1}\right)$ and $\operatorname{VGLUT} 2\left(A_{2}, B_{2}\right)$ immunolabeling in corresponding areas in the dorsal horn of segment L4. Medial is to the right and dorsal is upward. The photomicrographs in B are from the center of laminae V-VI and include a small part of lamina VII (cf. Fig. 3 D). I, lamina I; II, lamina II; III, lamina III; IV, lamina IV; V, lamina V; VI, lamina VI; VII, laminae VII. Calibration bar in $\mathrm{B}_{2}$ (valid for all photomicrographs), $100 \mu \mathrm{m}$. 
Fig. 5. Photomicrographs showing details of VGLUT1 $\left(\mathrm{A}_{1}, \mathrm{~B}_{1}\right)$ and VGLUT2 $\left(\mathrm{A}_{2}, \mathrm{~B}_{2}\right)$ immunolabeling in corresponding areas in the intermediate zone and ventral horn of segment C6. The photomicrographs in A are rotated (arrows show dorsal and medial) and show a small part of the ventral funiculus at the extreme right (cf. Fig. 3 B). In B, medial is to the right and dorsal is upward. VII, lamina VII; VIII, lamina VIII; IX, lamina IX. Calibration bar in $\mathrm{A}_{1}$ (valid for all photomicrographs), $100 \mu \mathrm{m}$.

Fig. 6. Photomicrographs showing details of VGLUT1 $\left(A_{1}, B_{1}, C_{1}\right)$ and VGLUT2 $\left(A_{2}, B_{2}, C_{2}\right)$ immunolabeling in corresponding areas of selected spinal cord nuclei in segment C2. Medial is to the right and dorsal is upward in all photomicrographs. $\mathrm{CeCv}$, central cervical nucleus, IBN, internal basilar nucleus; LCN, lateral cervical nucleus; LSN, Lateral spinal nucleus; pt, pyramidal tract; V, lamina V. Calibration bar in $\mathrm{A}_{1}$ (valid for all photomicrographs), $100 \mu \mathrm{m}$.

Fig. 7. Photomicrographs showing details of VGLUT1 $\left(A_{1}, B_{1}\right)$ and $\operatorname{VGLUT} 2\left(A_{2}, B_{2}\right)$ immunolabeling in corresponding areas of selected spinal cord nuclei in segment T8. Medial is to the right and dorsal is upward in all photomicrographs. $\mathrm{CC}$, column of Clarke; IML, intermediolateral nucleus; pt, pyramidal tract; V, lamina V; VII, lamina VII; X, lamina X. Calibration bar in $\mathrm{A}_{1}$ (valid for all photomicrographs), $100 \mu \mathrm{m}$.

Fig. 8. Merged confocal micrographs, obtained with a X100 oil immersion lens, showing single optical slices, $1 \mu \mathrm{m}$ thick, in the lateral cervical nucleus (sequential scanning, levels optimized and channels merged in Photoshop 7.0). Dorsal is upwards and medial is to the right. Spinocervical tract varicosities anterogradely labeled with choleragenoid (CTb, green) are not immunoreactive for VGLUT1 (A, red), but virtually all of them are immunoreactive for VGLUT2 (B, red; colocalization of CTb and VGLUT2 shown in yellow). The VGLUT1 labeling to the right in A locate in the adjacent lateral spinal nucleus. Calibration bar in $\mathrm{B}$ (valid for A and B), $10 \mu \mathrm{m}$.

Fig. 9. Confocal microscopy reveals co-expression of the vesicular glutamate transporters in a subpopulation of terminals. A and B from segment $\mathrm{C} 2$ of the spinal cord, show immunostaining for VGLUT1 and VGLUT2, respectively. An overlay is shown in C, a montage of six pictures obtained with a X10 lens (pinhole widely open, sequential scanning) and mounted in Photoshop CS (channel levels automatically optimized in Photoshop CS). The inset in $\mathrm{C}$ shows a z stack obtained with a X63 oil immersion lens (pinhole optimized for each 
laser to match the size of the optical slice in each channel, sequential scanning, levels automatically optimized in Photoshop CS). Note that the colocalization observed in the xy axis is also observed in the $\mathrm{xz}$ and yz axes, excluding the possibility of false colocalization due to tight apposition of terminals differently stained. I-IX indicate different spinal cord laminae; $\mathrm{CeCv}$, central cervical nucleus; DH, dorsal horn; IBN, internal basilar nucleus; LCN, lateral cervical nucleus; LSN, lateral spinal nucleus; VH, ventral horn; Calibration bars in A$\mathrm{C}, 160 \mu \mathrm{m}$, and $\mathrm{C}$ inset, $9.5 \mu \mathrm{m}$. 
Table 1. Antisera used for immunocytochemical detection of VGLUT1, VGLUT2 or CTb.

\begin{tabular}{|c|c|c|c|c|}
\hline Antigen & $\begin{array}{l}\text { Manufacturer/ } \\
\text { Producer }\end{array}$ & Prod.No. & Species & Immunizing antigen \\
\hline VGLUT1 & Bellocchio et al. 1998 & - & rabbit polyclonal & $\begin{array}{l}\text { GST fusion protein } \\
\text { containing amino acid } \\
\text { residues } 493-560 \text { of } \\
\text { VGLUT1 }\end{array}$ \\
\hline VGLUT1 & Synaptic Systems & 135003 & $\begin{array}{l}\text { rabbit polyclonal, } \\
\text { affinity purified }\end{array}$ & $\begin{array}{l}\text { GST fusion protein } \\
\text { containing amino acid } \\
\text { residues } 456-560 \text { of } \\
\text { rat VGLUT1 }\end{array}$ \\
\hline VGLUT1 & Chemicon & AB5905 & guinea pig polyclonal & $\begin{array}{l}\text { Synthetic peptide } \\
\text { containing amino acid } \\
\text { residues } 541-560 \text { of } \\
\text { rat VGLUT1 }\end{array}$ \\
\hline VGLUT2 & Fremeau et al. 2001 & - & rabbit polyclonal & $\begin{array}{l}\text { GST fusion protein } \\
\text { containing amino acid } \\
\text { residues 519-582 of } \\
\text { VGLUT2 }\end{array}$ \\
\hline VGLUT2 & Synaptic Systems & 135103 & $\begin{array}{l}\text { rabbit polyclonal, } \\
\text { affinity purified }\end{array}$ & $\begin{array}{l}\text { GST fusion protein } \\
\text { containing amino acid } \\
\text { residues 510-582 of } \\
\text { rat VGLUT2 }\end{array}$ \\
\hline $\mathrm{CTb}$ & Biogenesis & clone 2/63 & mouse monoclonal & native $\mathrm{V}$. cholera toxin \\
\hline
\end{tabular}


Table 2. Size of VGLUT1 immunolabeled varicosities in different areas of spinal gray matter $^{\mathbf{a}}$

\begin{tabular}{|c|c|c|c|c|c|c|c|}
\hline \multirow{2}{*}{$\begin{array}{l}\text { Location } \\
\text { (laminae) }\end{array}$} & \multirow{2}{*}{$\begin{array}{l}\text { Long diameter } \\
\qquad(\mu \mathrm{m} \pm \mathrm{SD})\end{array}$} & \multicolumn{6}{|c|}{ Statistical comparison $^{\mathbf{b}}$} \\
\hline & & 1 & 2 & 3 & 4 & 5 & 6 \\
\hline 1. I-II & $1.4 \pm 0.4$ & - & $* * *$ & $* * *$ & $* * *$ & & $* * *$ \\
\hline 2. III-IV & $2.2 \pm 0.8$ & $* * *$ & - & & & $* * *$ & $* * *$ \\
\hline 3. V-VI & $2.4 \pm 0.7$ & $* * *$ & & - & & $* * *$ & $* * *$ \\
\hline 4. VII & $2.5 \pm 1.1$ & $* * *$ & & & - & $* * *$ & $* * *$ \\
\hline 5. VIII & $1.6 \pm 0.4$ & & $* * *$ & $* * *$ & *** & - & $* * *$ \\
\hline 6. IX & $3.2 \pm 1.4$ & $* * *$ & $* * *$ & $* * *$ & $* * *$ & $* * *$ & - \\
\hline
\end{tabular}

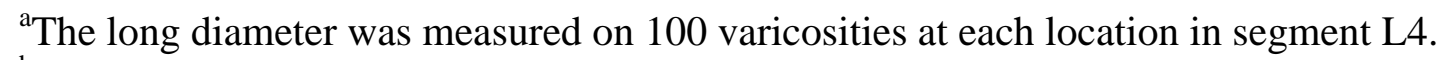
bStatistical comparison of long diameters (one-way ANOVA, Newman-Keul), asterisks indicate statistical difference between groups $(\mathrm{p}<0.001)$. 
Table 3. Size of VGLUT2 immunolabeled varicosities in different areas of spinal gray matter $^{\mathrm{a}}$

\begin{tabular}{|c|c|c|c|c|c|c|c|}
\hline \multirow{2}{*}{$\begin{array}{l}\text { Location } \\
\text { (laminae) }\end{array}$} & \multirow{2}{*}{$\begin{array}{l}\text { Long diameter } \\
\quad(\mu \mathrm{m} \pm \mathrm{SD})\end{array}$} & \multicolumn{6}{|c|}{ Statistical comparison $^{\mathbf{b}}$} \\
\hline & & 1 & 2 & 3 & 4 & 5 & 6 \\
\hline 1. I-II & $1.5 \pm 0.3$ & - & & & & & \\
\hline 2. III-IV & $1.4 \pm 0.4$ & & - & & & & $*$ \\
\hline 3. V-VII & $1.4 \pm 0.3$ & & & - & & & $*$ \\
\hline 4. VII & $1.5 \pm 0.3$ & & & & - & & \\
\hline 5. VIII & $1.5 \pm 0.4$ & & & & & - & \\
\hline 6. IX & $1.6 \pm 0.4$ & & $*$ & $*$ & & & - \\
\hline
\end{tabular}

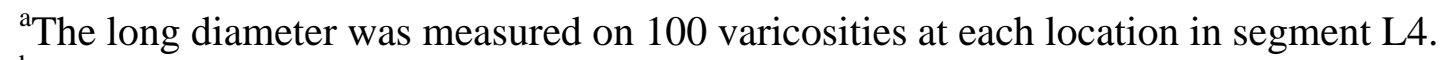
bStatistical comparison of long diameters (one-way ANOVA, Newman-Keul), asterisks indicate statistical difference between groups $(\mathrm{p}<0.05)$. 
Table 4. Density of terminals co-containing VGLUT1 and VGLUT2

\begin{tabular}{lcc}
\hline Location & $\begin{array}{l}\text { No. of double labeled terminals } \\
\text { per optical slice }( \pm \text { SD) }\end{array}$ & Statistical comparison* \\
\hline & $4.9 \pm 2.5$ & $\mathrm{p}=0.00018$ \\
III-IV & $0.22 \pm 0.17$ & \\
IX & & \\
\hline
\end{tabular}

*Students $\mathrm{t}$ test, $\mathrm{n}=7$ in each group. 


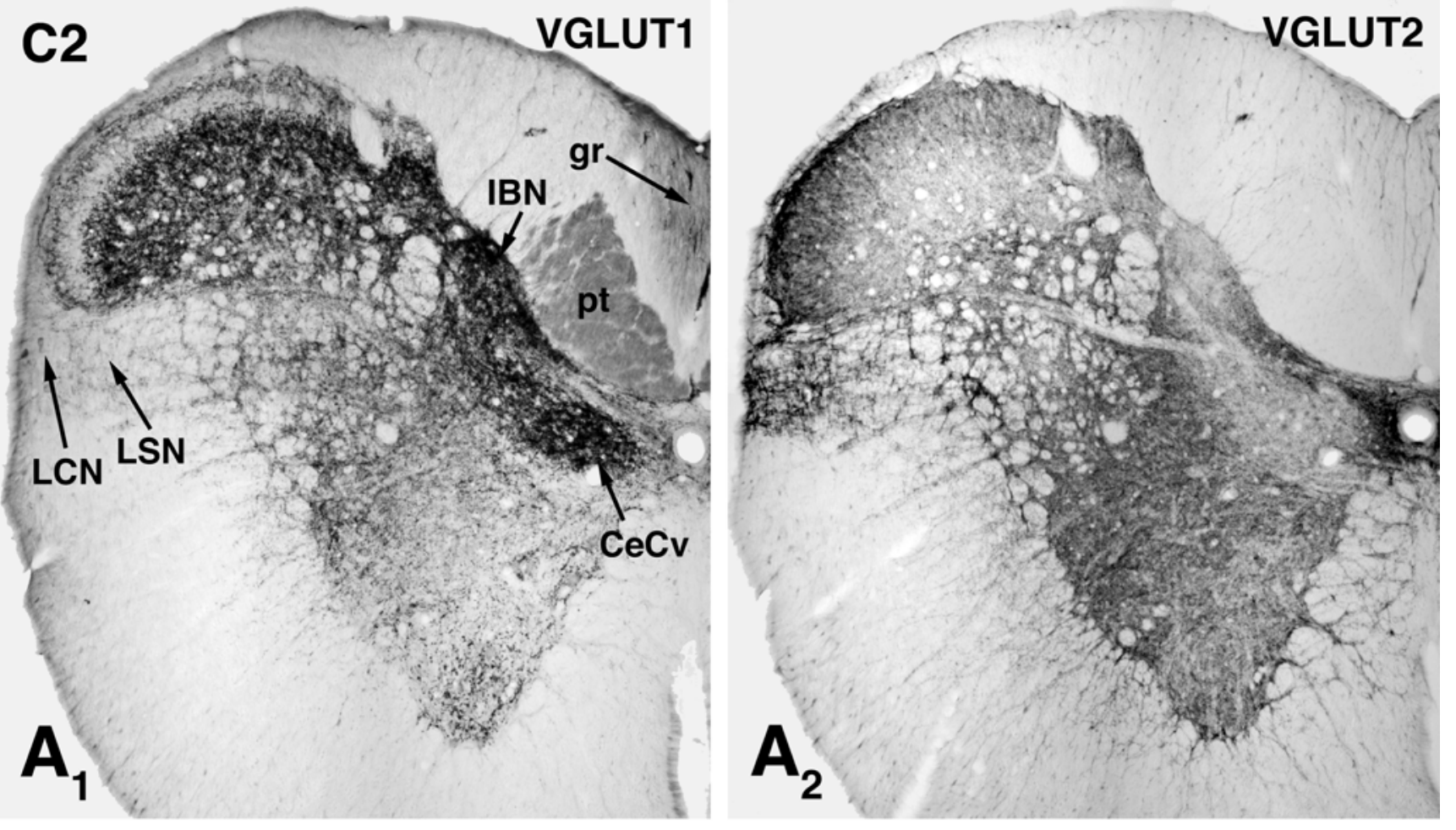

\section{C6}
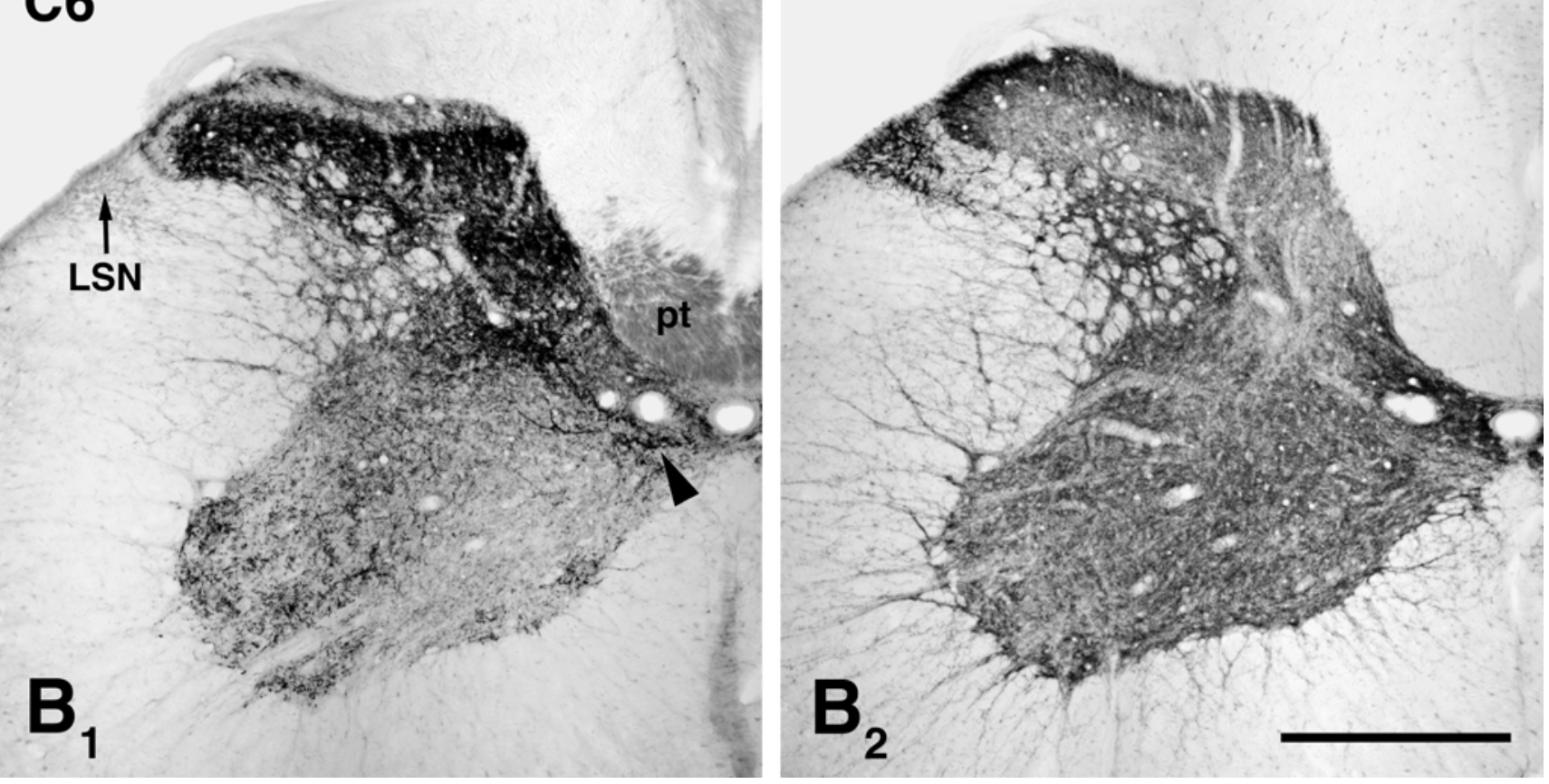


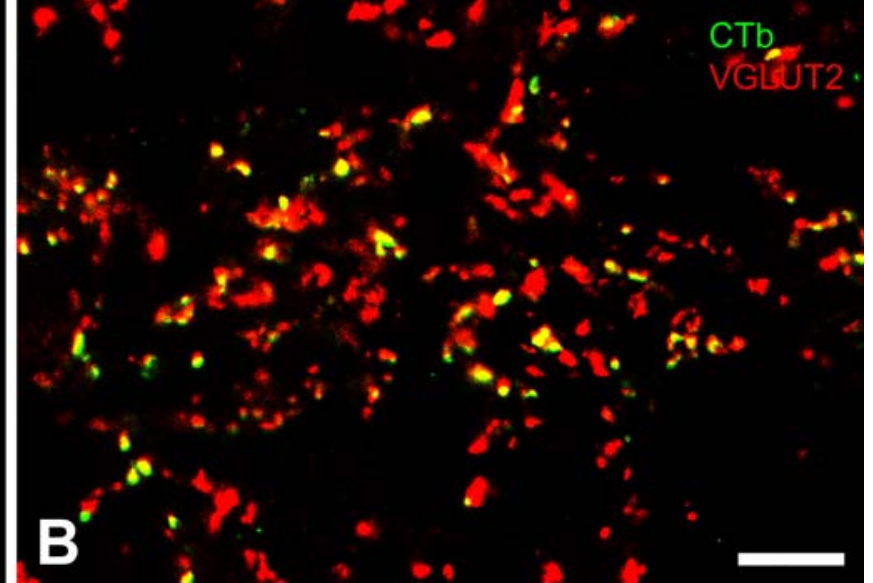




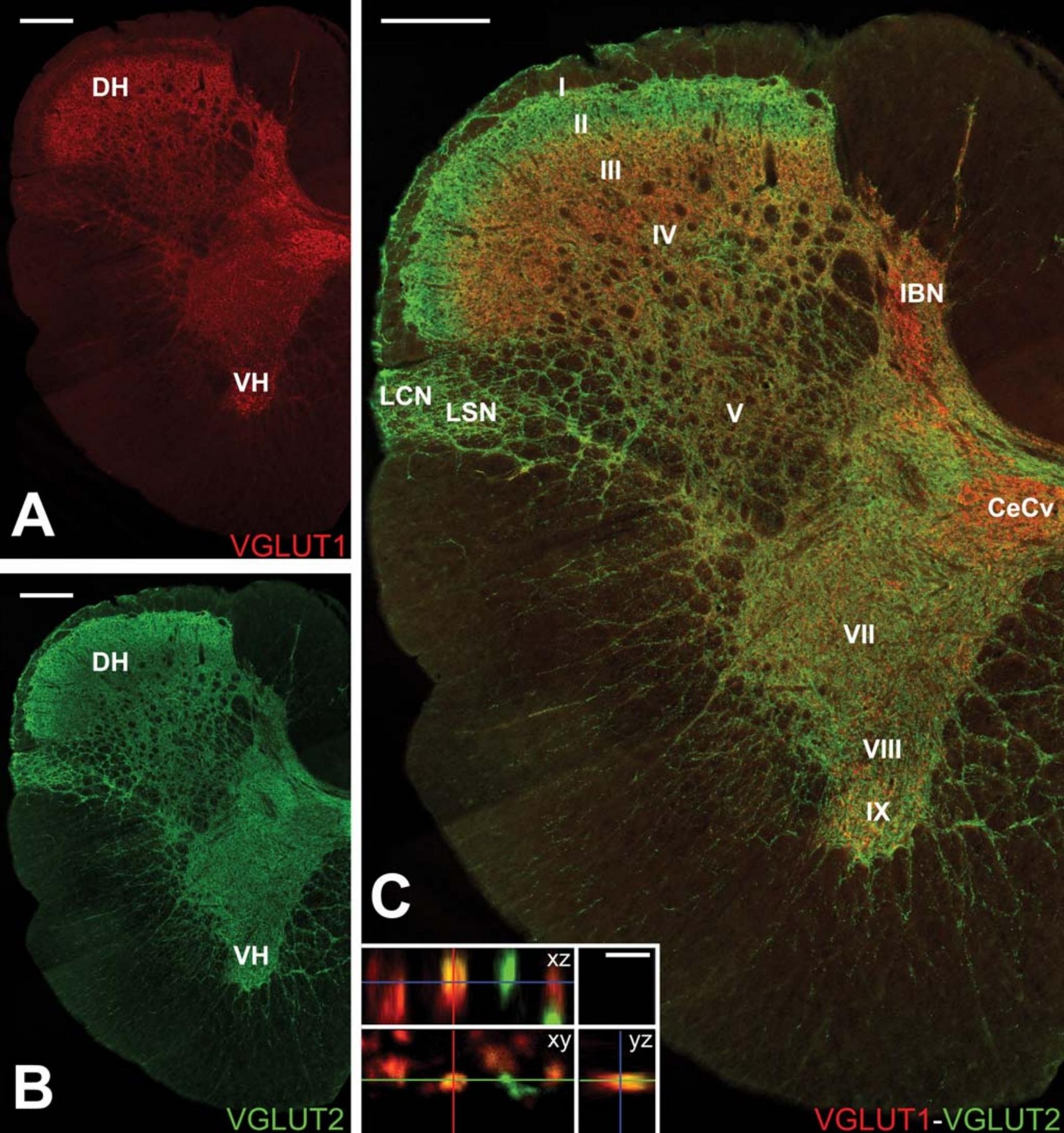

